\title{
Empirical Study on Investment Pattern towards Health Insurance at Salem district, Tamilnadu.
}

\author{
M. Priyadarsini \\ -Assistant Professor in MBA,Muthayammal Engineering College,Salem
}

\begin{abstract}
In this contemporary world emergence of new disease are uncertain. More amenities are available today to overcome but it's too pricey. Health insurance is the provision to prevail over numerous diseases in the world. Health insurance enables to overcome the pre-admission \& post-admission price of hospitalization. Health insurance shield premium are too costly, hence some people are not aware of the health insurance benefits .This research paper had made an attempt to explore the investment behavior of investors towards health insurance in Salem district ,Tamil Nadu state. The primary data collection made through structured questionnaire. The opinions of 200 respondents were considered for the analysis. Through this analysis it was found that consciousness's of health insurance are lacking among the public of Salem district, as well as their income level do not support for high premium policy
\end{abstract}

Keywords: Awareness, Health insurance, Income, Investment behavior.

\section{Introduction}

In the mechanical world humans are worried to enhance their earning capacity to lead a comfortable life in the upcoming world but they have completely forgotten that health is a wealth. Health plays a vital role for the gratification of life. Today's life is uncertain due to emergence of numerous diseases.

From the past decay the food habits of the humans has been changed tremendously. Hence today's food habits play a dominant role in affecting the individual's health problems. Mostly today all the epoch categories are affected by food poison, diarrhea, obesity, deficiency of vitamins due to the consumption of junk foods.

Gratefully, these days technology development has pave way to overcome the numerous diseases by the emergence of specialty hospitals with experts in the specific fields of human organs, hence this is possible only if we have sufficient money or by holding a health care policy. An individual can face any time an accident, neural disease, strokes, diabetics, cancer and so on. Any class of people, either middle or high or low, if they met an accident, same kind of treatment have to be taken, there is no treatment provided as per their income level. In case of wealthy people, they are able to meet out the hospitalization expense at any cost to recover. In case of lower income group, it's impossible to meet out these expenses, as they lead a budgeted life; it's difficult to meet any unexpected hospitalization expense.

To overcome these circumstances without any difficulty and to lead a happy life, health awareness is needed. Therefore the middle income group categories have to hold a health care policy to overcome this unexpected health care expenditure. If an individual insures for health problem, then he will be able to lead peaceful life with a calm mind, as well as guaranteed to stay financially secured.

Health insurance plan provided overall protection shield for the entire family on the payment of a single premium under a single sum insured. The sum insured floats among the family members insured. It's just one more way to tighten the family bonds. Health insurance combines the financial prudence of a significant tax saving with the necessary health cover for a family. Health policy offers dual benefits with affordable premium through health protection shield for entire family and exemption from tax. Therefore health awareness is slowly stepping in to the lifestyle of Salem district public

\section{Review Of Literature:}

Banerjee et al. (2009) ${ }^{1}$ find that out-of pocket health expenditure represents about $10 \%$ of total household expenditure among slum dwellers in Hyderabad, India.

Ippolito (1992) ${ }^{2}$ says that fund/scheme selection by investors is based on past performance of the funds and money flows into winning funds more rapidly than they flow out of losing funds

\footnotetext{
${ }^{1}$ Banerjee, Abhijit, , Esther Du.o, Rachel Glennerster, and Cynthia Kinnan (2009)..The Miracle of micro.nance? Evidence from a Randomized Evaluation..mimeo,MIT.

${ }^{2}$ Ippolito, R. (1992). Consumer reaction to measures of poor quality: Evidence from Mutual Funds. Journal of Law and Economics, 35, 45-70.
} 
Omar and Frimpong (2006) ${ }^{3}$ stressed the importance of life insurance and regarded it as a saving medium, financial investment, or a way of dealing with risks

Black and Skipper (2000) $)^{4}$, is of opinion that life insurance becomes the mechanism to ensure a continuous stream of income to the beneficiaries. The two main services provided by life insurance: income replacement for premature death and long-term savings instruments.

Rajkumari (2007) $)^{5}$ in her study undertaken to identify the customers' attitude towards purchase of insurance products concludes that there is a low level of awareness about insurance products among customers in India.

Browne et al. (1993) has studied based on 45 countries for two separate time periods (1980 and 1987) concluded that income and social security expenditures are significant determinants of insurance demand, however, inflation has a negative correlation.

Using detailed diaries kept by rural households in western Kenya, Dupas \& Robinson (2009) ${ }^{6}$ find that health expenditure represents $8 \%$ of total household expenditure.

Shen \& McFeeters 2006, Cunningham $2009^{7}$ has identify to give some perspective, in the United States, out-of-pocket health expenditure, excluding insurance premiums, is typically considered unaffordable if it is more than $5 \%$ of family income

\section{II.1 NEED OF THE STUDY:}

1.The result of this research would help the company to have better understanding of investment behavior of investor's towards health insurance.

2.The study helps the company by creating awareness about the investors of different ages and income level.

3.The study also enables the company to focus the investor's preference and expectations on the products which they offer.

4.This study will help to create awareness of money matter incorporation

\section{II.2 OBJECTIVES OF THE STUDY:}

The overall objective of the study is to know the investment behaviour of Health Insurance among the Salem society. To attain this overall objective, the study aims at the following specific objectives:

1. To identify the individual purpose for investing in Health Insurance.

2. To discover the importance of health insurance in Salem society.

3. To make out whether income standard affects in investing health insurance plan.

\section{II.3 LIMITATIONS OF THE STUDY:}

This study is confined to a particular selected region, that is, Salem District and hence conclusions are drawn with due care when an attempt is made to generalize the results. Further, the findings may not be applicable to other regions. Due to paucity of time and fund, the size of the sample is restricted to 200 . The study is confined only about the investment behaviour towards health insurance and therefore the outcomes cannot be generalized to other category. As this study is concerned with financial matters, investors' reluctance to disclose information on some items in the questionnaire had to be encountered. Many of the responded questionnaires could not be considered as the respondents were not willing to disclose the amount of investments in scheme. The response from the investors may not accurate.

\section{II.4 RESEARCH METHODOLOGY:}

The nature of the study is descriptive analytical research. The study is mainly based on primary data. Primary data has been collected from various people of Salem society by issuing questionnaires and getting it filled by them. The collected data was classified and analysed cautiously. Questionnaire is constructed, in such a way objectives are clear to the respondents. In this research, the questionnaire was formed as a direct and structured one. All questions in questionnaire were close ended questions. Open-ended question has been used only for deriving suggestions from the respondents. The method used for collecting requisite data is 'Convenience Sampling', which is a type of non-probability sampling technique.

Research design: The research design is to meet out the objective. The research study has carried out at Salem district in Tamilnadu state. The sampling unit of the study is combination of policy holders as well as non policy

\footnotetext{
${ }^{3}$ Omar, O. E. and Owusu-Frimpong, N. (2007). Using the theory of reasoned action to evaluate consumer

attitudes and purchase intention towards life insurance in Nigeria. The Service Industries Journal, 27 (7), 1-1 14.

${ }^{4}$ Black, K. and Skipper, H. D. (2000). Life and Health Insurance. Upper Saddle River, NJ: Prentice-Hall.

${ }^{5}$ Rajkumari. (2007). Stages in Life Cycle and Investment Pattern. The Indian Journal of Commerce, 51 (2 \& 3), 27-36

${ }^{6}$ Dupas, Pascaline, and Jonathan Robinson (2009). .Savings Constraints andMicroenterprise Development: Evidence from a .eld experiment in Kenya.. NBER Working Paper 14693.

${ }^{7}$ Shen Y, McFeeters J. (2006). .Out.of.Pocket Health Spending Between Low. And Higher. Income populations: Who Is at Risk of Having High Expenses and High Burdens?,.Medical Care, Vol. 44, No. 3, pp. 200.209.
} 
holders. The sampling technique used to collect facts is convenience sampling. The number of samples taken for research study is 200 respondents. The data has been collected through structured questionnaire. If individual holds health insurance can escape from medical expense in losing assets or paying out of pocket. The research study is to find out which factor is affecting health insurance \& reasons behind not having.

Research Problem : Day by day, health expenditure plays important role in financial planning of a individual income. Most of them meet out the health care expense from their pockets. In today's individual life, loses all his personal assets due to increase in medical expenses. The individual does not hold insurance policy due to various factors. The individuals are not aware that health insurance premium is less than the amount spends towards medical expenses. For the successfully implementation of health insurance coverage, it is necessary to understand basic dynamics of investor's behaviour, preferences, acceptability and pricing of health insurance products.

Tools and Techniques Of Data Analysis: The Statistical Analysis carried out in the study is being done using MS-Excel and SPSS (Statistical Package for Social Science) Software. The Statistical techniques like: percentage, Chi-square test. Analysed \& interpreted data have been presented in the form of tables, charts and figures.

\section{Data Analysis And Interpretation \\ TABLE:3.1 \\ AWARENESS OF HEALTH INSURANCE}

\begin{tabular}{|c|c|c|}
\hline Awareness & No. of Respondents & Percentage \\
\hline Yes & 170 & 84.5 \\
\hline No & 30 & 15.5 \\
\hline Total & 200 & 100 \\
\hline
\end{tabular}

Sources: Primary Data

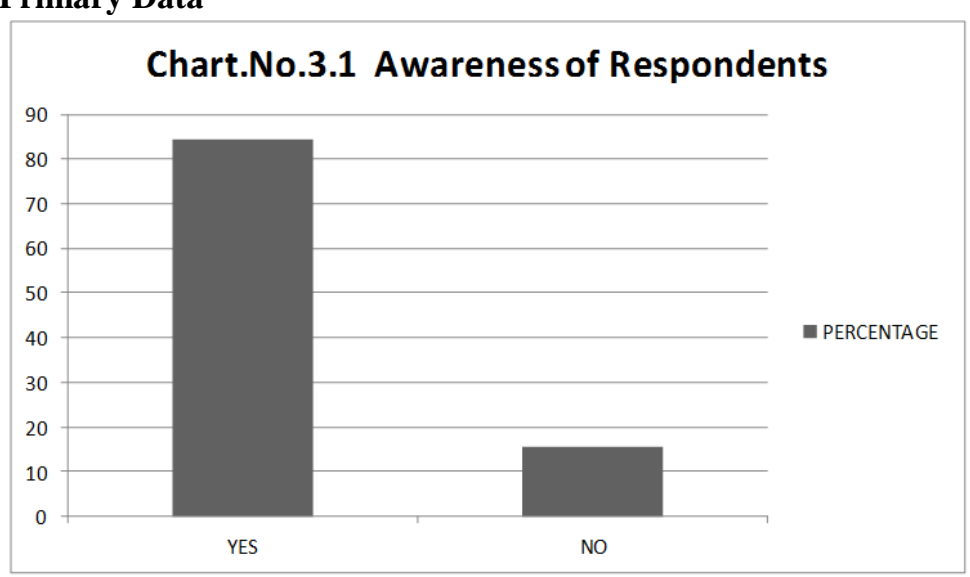

Inference:

The above charts explores regarding the awareness of Salem society towards health insurance. In Salem society, out of 200 respondents, $84.5 \%$ are aware of health insurance where as remaining $15.5 \%$ are not aware of health insurance

TABLE.NO.3.2

HEALTH INSURER'S OF SALEM SOCIETY

\begin{tabular}{|c|c|c|}
\hline $\begin{array}{c}\text { Insurer of Health } \\
\text { Insurance }\end{array}$ & No. of respondent & Percentage \\
\hline Yes & 121 & 71.2 \\
\hline No & 49 & 28.8 \\
\hline Total & 170 & 100 \\
\hline
\end{tabular}

Source: Primary data 


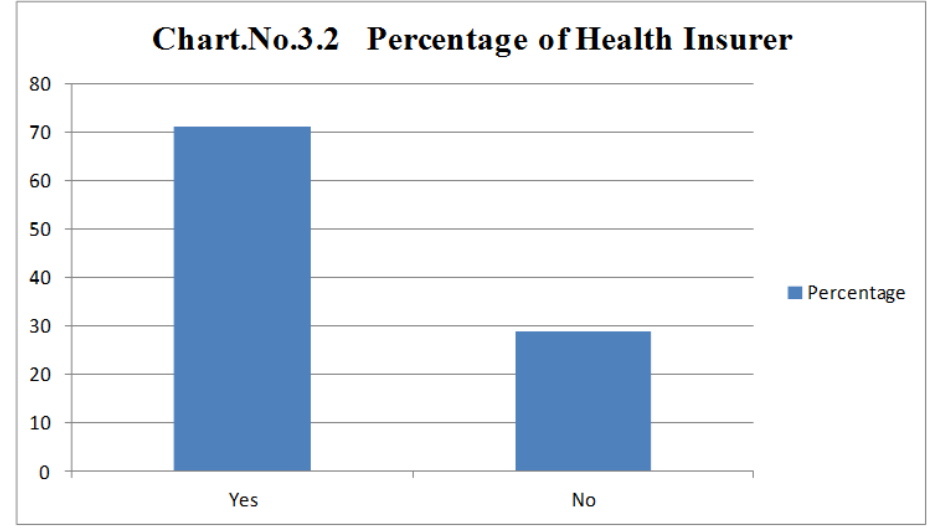

Inference:

The chart depict that ,in 200 respondents , 170 respondent are aware of health insurance where only 71.2\% respondent have invested in health insurance and remaining 28.8 percent are aware of health insurance but does not make investment in health insurance due to some deficiency.

TABLE.NO.3.3 REASON FOR INVESTING IN HEALTH INSURANCE POLICY

\begin{tabular}{|l|c|c|}
\hline \multicolumn{1}{|c|}{ Reason } & No. of Respondents & Percentage \\
\hline Risk cover & 26 & 21.5 \\
\hline Tax benefits & 10 & 8.3 \\
\hline $\begin{array}{l}\text { To protect against unexpected high } \\
\text { Medical expense }\end{array}$ & 67 & 55.4 \\
\hline All the above & 18 & 14.9 \\
\hline Total & 121 & 100 \\
\hline
\end{tabular}

Source: Primary data

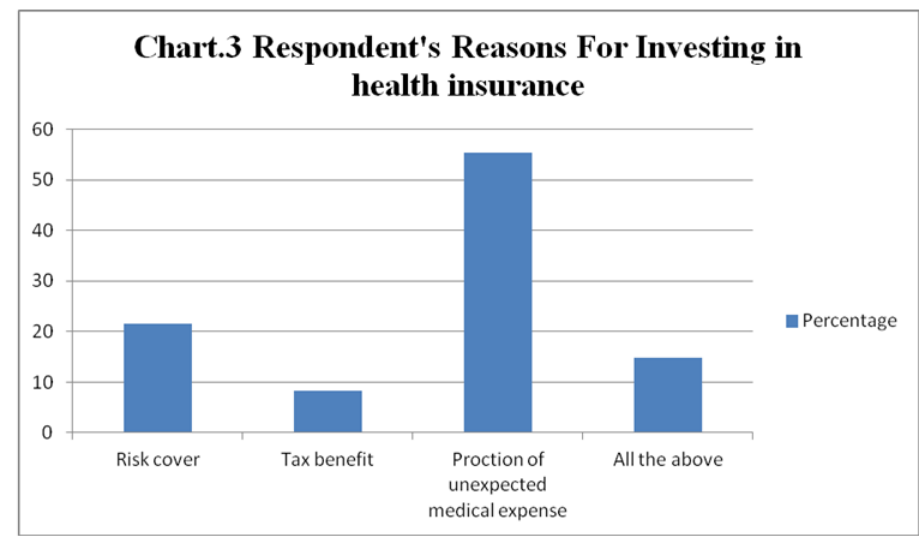

Inference:

This chart represents the respondents make investments for various reasons like risk cover, tax benefit, protection against unexpected medical expense .The respondent invest in health insurance due to risk cover is $21.5 \%, 8.3 \%$ of respondents invest due to tax benefit, where $55.4 \%$ invest due to protection against unexpected high medical expense and $14.9 \%$ invest due to above all reasons

TABLE 3.4 IMPORTANCE OF POLICY

\begin{tabular}{|l|c|c|}
\hline Importance & No. of Respondent & Percentage \\
\hline Very important & 107 & 53.5 \\
\hline Important & 71 & 35.5 \\
\hline Slightly important & 9 & 4.5 \\
\hline Unimportant & 10 & 5.0 \\
\hline Unnecessary & 3 & 1.5 \\
\hline Total & 200 & 100 \\
\hline
\end{tabular}

Source :Primary data 


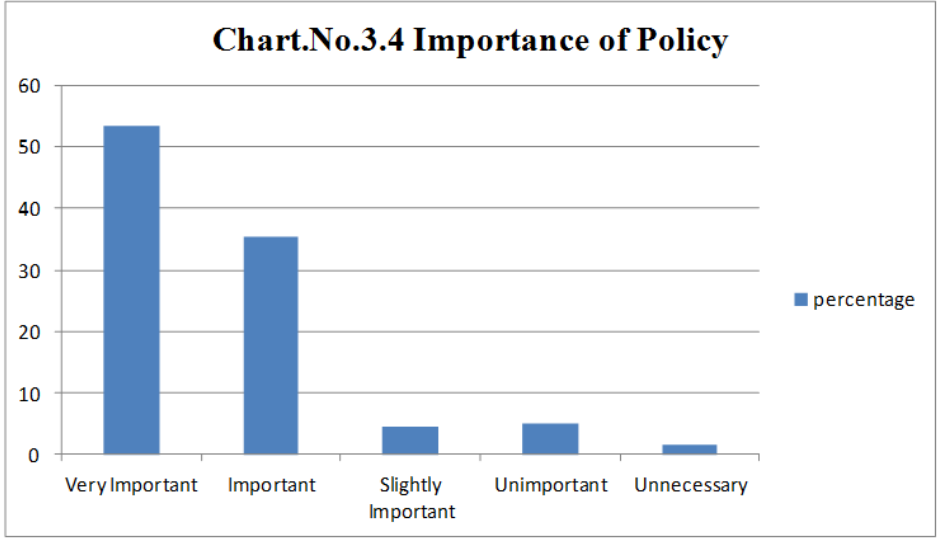

\section{Inference:}

The above chart portrays, in 200 respondents, $53.5 \%$ of them, felt that holding health insurance policy is very important, where $35.5 \%$ felt important, $4.5 \%$ felt slightly important, $5 \%$ felt unimportant and $1.5 \%$ felt unnecessary. From the chart it's understood that investor assign lot of importance to hold a health insurance but all do not hold health insurance policy.

\section{CHI-SQUARE TEST:}

Hypothesis: Income \& Interest

Ho: Level of income is independent in investing health insurance.

H1: Level of income is dependent in investing health insurance.

IV. Result:

TABLE.NO.3.5 CHI SOUARE TEST

\begin{tabular}{|c|c|c|c|}
\hline Calculated Value & Table Value & Degree of freedom & Level of significance \\
\hline 20.305 & 9.448 & 4 & 5 \\
\hline
\end{tabular}

From above table, it is clear that calculated value of chi square is greater than table value at 4 degree of freedom and 5\% level of significance. Therefore null hypothesis is rejected, alternate hypothesis accepted. It can be completed that there is a significance relationship between income and interest.

\subsection{FINDINGS:}

1. In this research, $53 \%$ of the respondents belong to the age group below $30,24 \%$ to the age group $31-40,12 \%$ belong to the age group of 41-50 and the rest to the age group of above 50 .

2. The knowledge and Confidence of respondents about health insurance is good. It has found that awareness of health insurance is fine where the preference is average

3. Most respondents' know about health insurance but some of them don't have any policy

because of low awareness or lack of information regarding health insurance.

4. Research indicates that there are clear possibilities for health insurance market in India; there are also possibilities for the public and private health insurance companies.

5. It can be said that income of respondents plays a vital role in investing health insurance.

\subsection{SUGGESTIONS:}

1. Health Insurance companies should apply new marketing strategies for their products.

2. It should offer higher insurance amount of health Insurance at lower premium for middle class and lower middle class of society.

3. It should increase the number of hospitals under coverage.

4. It should provide an easy claim statement system and low documentation.

5. Companies should not only focus the town area investors, it should also focus on the investor of rural area.

6. Make easy and transparent claim settlement procedure.

\subsection{CONCLUSION:}

Even though health day is celebrated on $7^{\text {th }}$ April, many of the individuals are unaware of health insurance benefits, people under poverty line are provide a medical insurance claim named as Kalaingnar Kapiedu Titam. Elite people of the society will be affordable for expensive medical treatment, whereas the 
middle income group people suffer a lot due to uncertain health problem which acquire high medical expenses. Hence this research study was conducted to analyses the awareness of the health insurance among the public of Salem district of Tamilnadu at the same time this research would enable the insurance company to concentrate on middle income groups to increase their policies

\section{References:}

[1]. Beri G.C (2009), Marketing Research, 4th Edition, pp.369-380, Tata McGraw Hill, New Delhi.

[2]. Jain Nishant; Bhat Ramesh (2006). The paper entitled "Factoring affecting the Demand for Health Insurance in a Micro Insurance Scheme", available at www.iimahd.ernet.in/publications/data/2006-07-02rbhat.pdf

[3]. Sukummar Vellakal, December 2007. "Health Insurance Schemes in India: An Economic Analysis of demand management under risk. pooling.and.adverse.selection", available at http://www.isec.ac.in/Health insurence schemes in India.pdf

[4]. A.O. Okaro, C.C. Ohagwu and J. Njoku, 2010."Awareness and Perception of National Health Insurance Scheme (NHIS) Among.Radiographers.in.South.East.Nigeria", available at http://www.eurojournals.com/ajsr 8 03.pdf

[5]. Health Behavior in Developing Countries-Pascaline Dupas-UCLA \& NBER,April 5, 2011Prepared for the Annual Review of Economics, Vol. 3 (Sep. 2011)

[6]. What Is thePupose of Health Insurance?-By Barbara Aufiero, e How Contributor 